
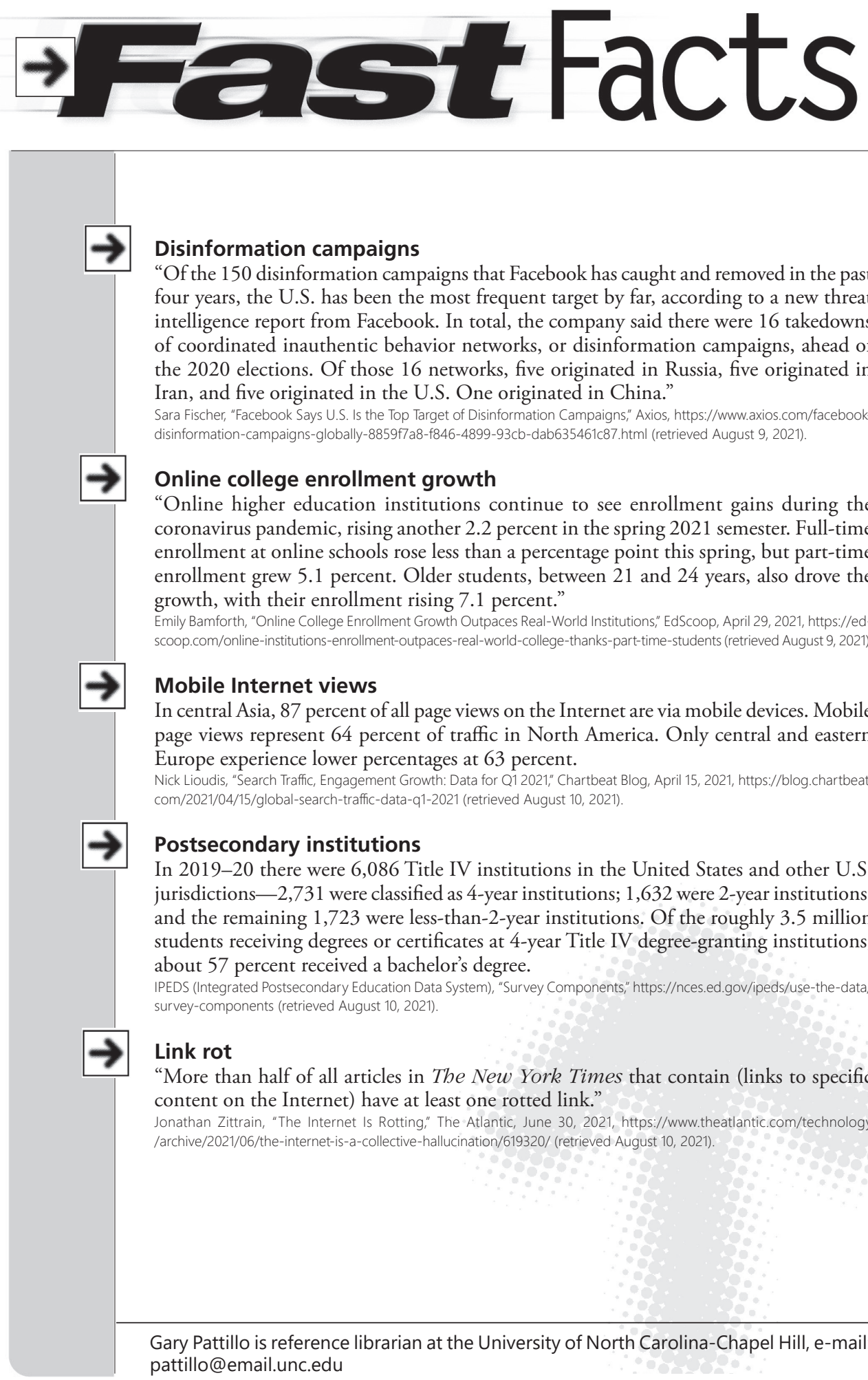

Disinformation campaigns

"Of the 150 disinformation campaigns that Facebook has caught and removed in the past four years, the U.S. has been the most frequent target by far, according to a new threat intelligence report from Facebook. In total, the company said there were 16 takedowns of coordinated inauthentic behavior networks, or disinformation campaigns, ahead of the 2020 elections. Of those 16 networks, five originated in Russia, five originated in Iran, and five originated in the U.S. One originated in China."

Sara Fischer, "Facebook Says U.S. Is the Top Target of Disinformation Campaigns," Axios, https://www.axios.com/facebookdisinformation-campaigns-globally-8859f7a8-f846-4899-93cb-dab635461c87.html (retrieved August 9, 2021).

\title{
Online college enrollment growth
}

"Online higher education institutions continue to see enrollment gains during the coronavirus pandemic, rising another 2.2 percent in the spring 2021 semester. Full-time enrollment at online schools rose less than a percentage point this spring, but part-time enrollment grew 5.1 percent. Older students, between 21 and 24 years, also drove the growth, with their enrollment rising 7.1 percent."

Emily Bamforth, "Online College Enrollment Growth Outpaces Real-World Institutions," EdScoop, April 29, 2021, https://ed scoop.com/online-institutions-enrollment-outpaces-real-world-college-thanks-part-time-students (retrieved August 9, 2021).

\section{Mobile Internet views}

In central Asia, 87 percent of all page views on the Internet are via mobile devices. Mobile page views represent 64 percent of traffic in North America. Only central and eastern Europe experience lower percentages at 63 percent.

Nick Lioudis, "Search Traffic, Engagement Growth: Data for Q1 2021," Chartbeat Blog, April 15, 2021, https://blog.chartbeat. com/2021/04/15/global-search-traffic-data-q1-2021 (retrieved August 10, 2021)

\section{Postsecondary institutions}

In 2019-20 there were 6,086 Title IV institutions in the United States and other U.S. jurisdictions-2,731 were classified as 4-year institutions; 1,632 were 2-year institutions; and the remaining 1,723 were less-than-2-year institutions. Of the roughly 3.5 million students receiving degrees or certificates at 4-year Title IV degree-granting institutions, about 57 percent received a bachelor's degree.

IPEDS (Integrated Postsecondary Education Data System), "Survey Components," https://nces.ed.gov/ipeds/use-the-data/ survey-components (retrieved August 10, 2021).

\section{Link rot}

"More than half of all articles in The New York Times that contain (links to specific content on the Internet) have at least one rotted link."

Jonathan Zittrain, "The Internet Is Rotting," The Atlantic, June 30, 2021, https://www.theatlantic.com/technology /archive/2021/06/the-internet-is-a-collective-hallucination/619320/ (retrieved August 10, 2021).

Gary Pattillo is reference librarian at the University of North Carolina-Chapel Hill, e-mail: pattillo@email.unc.edu 